\title{
Transmyocardial revascularization to enhance myocardial vasculogenesis and hemodynamic function
}

\author{
Pavan Atluri, MD, Corinna M. Panlilio, BA, George P. Liao, MB, Eric E. Suarez, MD, Ryan C. McCormick, BS, \\ William Hiesinger, MD, Jeffrey E. Cohen, BA, Maximilian J. Smith, Abha B. Patel, BS, Wei Feng, MD, and \\ Y. Joseph Woo, MD
}

Supplemental material is available online.
From the Division of Cardiovascular Surgery, Department of Surgery, University of Pennsylvania School of Medicine, Philadelphia, Pa.

Supported in part by grants from the $\mathrm{Na}$ tional Institutes of Health National Heart Lung and Blood Institute/Thoracic Surgery Foundation for Research and Education (HL072812, YJW), unrestricted investigational grant from Cardiogenesis Corporation (YJW), and National Institutes of Health, National Heart Lung Blood Institute-Ruth L. Kirschstein National Research Service Award (Individual Fellowship 1 F32 HL79769-01, PA).

Received for publication May 24, 2007; revisions received Sept 11, 2007; accepted for publication Sept 24, 2007.

Address for reprints: Y. Joseph Woo, MD, Assistant Professor of Surgery, Division of Cardiothoracic Surgery, Department of Surgery, University of Pennsylvania, Silverstein 6, 3400 Spruce St, Philadelphia PA 19104 (E-mail: wooy@uphs.upenn.edu).

J Thorac Cardiovasc Surg 2008;135:283-91 $0022-5223 / \$ 34.00$

Copyright $(2) 2008$ by The American Association for Thoracic Surgery

doi:10.1016/j.jtcvs.2007.09.043
Objective: A significant number of patients have coronary artery disease that is not amenable to traditional revascularization. Prospective, randomized clinical trials have demonstrated therapeutic benefits with transmyocardial laser revascularization in this cohort. The molecular mechanisms underlying this therapy, however, are poorly understood. The focus of this study was evaluation of the proposed vasculogenic mechanisms involved in transmyocardial laser revascularization.

Methods: Male Yorkshire pigs $(30-35 \mathrm{~kg}, \mathrm{n}=25)$ underwent left thoracotomy and placement of ameroid constrictors around the proximal left circumflex coronary artery. During the next 4 weeks, a well-defined region of myocardial ischemia developed, and the animals underwent a redo left thoracotomy. The animals were randomly assigned to sham treatment (thoracotomy only, control, $\mathrm{n}=11$ ) or transmyocardial laser revascularization of hibernating myocardium with a holmium:yttrium-aluminum-garnet laser $(\mathrm{n}=14)$. After an additional 4 weeks, the animals underwent median sternotomy, echocardiographic analysis of wall motion, and hemodynamic analysis with an ascending aortic flow probe and pulmonary artery catheter. The hearts were explanted for molecular analysis.

Results: Molecular analysis demonstrated statistically significant increases in the proangiogenic proteins nuclear factor $\kappa \mathrm{B}(42 \pm 27$ intensity units vs $591 \pm 383$ intensity units, $P=.03)$ and angiopoietin $1(0 \pm 0$ intensity units vs $241 \pm 87$ intensity units, $P=.003$ ) relative to sham control values with transmyocardial laser revascularization within the ischemic myocardium. There were also increases in vasculogenesis $(18.8 \pm 8.7$ vessels/high-power field vs $31.4 \pm 10.2$ vessels/high-power field, $P=.02)$, and perfusion $\left(0.028 \pm 0.009 \mu \mathrm{m}^{3}\right.$ blood $/ \mu \mathrm{m}^{3}$ tissue vs $0.044 \pm 0.004$ $\mu \mathrm{m}^{3}$ blood $/ \mu \mathrm{m}^{3}$ tissue, $\left.P=.01\right)$. Enhanced myocardial viability was demonstrated by increased myofilament density $(40.7 \pm 8.5$ cardiomyocytes/high-power field vs $50.8 \pm 7.5$ cardiomyocytes/high-power field, $P=.03$ ). Regional myocardial function within the treated territory demonstrated augmented contractility. Global hemodynamic function was significantly improved relative to the control group with transmyocardial laser revascularization (cardiac output $2.1 \pm 0.2 \mathrm{~L} / \mathrm{min}$ vs $2.7 \pm 0.2 \mathrm{~L} / \mathrm{min}$, $P=.007$, mixed venous oxygen saturation $64.7 \% \pm 3.6 \%$ vs $76.1 \% \pm 3.4 \%, P=.008$ ).

Conclusion: Transmyocardial laser revascularization with the holmium-YAG laser enhances perfusion, with resultant improvement in myocardial contractility.

$\mathrm{T}$ The latest "Heart Disease and Stroke Statistics—2007 Update" from the American Heart Association estimates that there are 15.8 million Americans with coronary artery disease. ${ }^{1}$ We have made significant advances in our ability to treat ischemic myocardial disease with both coronary artery bypass grafting and percutaneous coronary intervention. Millions of Americans, however, have intractable angina and heart failure not amenable to revascularization with coronary artery bypass grafting or percutaneous coronary intervention. 


$$
\begin{aligned}
& \text { Abbreviations and Acronyms } \\
& \begin{aligned}
\mathrm{EPC} & =\text { endothelial progenitor cell } \\
\mathrm{Ho}: \mathrm{YAG} & =\text { holmium:yttrium-aluminum-garnet } \\
\mathrm{hpf} & =\text { high-power field } \\
\mathrm{iu} & =\text { intensity units } \\
\mathrm{NF} \kappa \mathrm{B} & =\text { nuclear factor } \kappa \mathrm{B} \\
\mathrm{TMR} & =\text { transmyocardial laser revascularization } \\
\mathrm{VEGF} & =\text { vascular endothelial growth factor }
\end{aligned}
\end{aligned}
$$

Transmyocardial laser revascularization (TMR) uses laser energy to create transmural channels through the ventricular free wall. This therapy originally attempted to replicate blood flow in the reptilian heart, in which direct myocardial sinusoids provide oxygenated blood directly from the left ventricle. ${ }^{2}$ Numerous randomized, prospective clinical trials have shown significant improvements in angina, rehospitalizations, function, and event-free survival after TMR ${ }^{3-7}$ The Society of Thoracic Surgeons working group on evidence-based surgery has recommended TMR as therapy for patients with refractory angina who cannot undergo revascularization. ${ }^{8}$

The lased myocardial channels are not patent 2 weeks after TMR according to histologic evaluation, raising the question of the true molecular mechanism underlying the clinical improvements. ${ }^{9-11}$ Previous studies have provided preliminary data for TMR-mediated vasculogenesis. These studies used basic, inferential assays to study vasculogenesis. With a porcine model of ischemic heart failure, we sought to elucidate clearly and definitively the changes in molecular biology and cellular and global physiology induced by transmyocardial holmium:yttrium-aluminum-garnet (Ho:YAG) laser revascularization. Our study focused on endothelial progenitor cell (EPC) upregulation, vasculogenic chemokine expression, neovasculogenesis, and enhanced perfusion as mediators of improved contractility after TMR.

\section{Materials and Methods Animal Care and Biosafety}

Male Yorkshire pigs (30-35 kg) were obtained from Archer Farms (Darlington, Md). This protocol was approved by the Institutional Animal Care and Use Committee of the University of Pennsylvania. All animals received humane care and treatment in accordance with the "Guide for the Care and Use of Laboratory Animals" (www. nap.edu/catalog/5140.html). Measurements were performed by blinded investigators.

\section{Induction of Myocardial Dysfunction}

Male Yorkshire pigs were administered ketamine, medetomidine hydrochloride (INN medetomidine), and thiopental, were endotracheally intubated, and were maintained on inhaled isoflurane $(1.5 \%-3.0 \%)$. A left fourth interspace thoracotomy was performed to expose the lateral left ventricle. The atrioventricular groove was stabilized, and the proximal left circumflex coronary artery was dissected free. A titanium ameroid constrictor $(2.5-3.0 \mathrm{~mm}$; Research
Instruments SW, Escondido, Calif) was placed around the vessel to provide a close fit without compromising the lumen $(n=25)$. The chest was closed in three layers over a temporary $28 \mathrm{~F}$ thoracostomy tube, and the animal was allowed to recover. The ameroid constrictor occluded the circumflex coronary artery during the course of 4 weeks, thereby causing wall motion abnormalities and myocardial dysfunction to develop. ${ }^{12-14}$

Four weeks after the initial operation, the animals underwent a redo left thoracotomy, and the ventricle was dissected free of adhesions. At this stage, the hearts grossly manifested myocardial dysfunction consistent with myocardial ischemia in the circumflex distribution. Wall motion abnormality was confirmed with echocardiography. The areas of ischemia and of wall motion abnormality, a measure of ischemia, were equivalent between the groups. An oximetric continuous cardiac output pulmonary arterial catheter (Edwards Lifesciences, Irvine, Calif) was placed though the left internal jugular vein, and an arterial line was inserted to confirm equivalent baseline myocardial function. Statistical analysis demonstrated no differences between control and TMR groups in baseline cardiac output $(3.8 \pm 0.3 \mathrm{~L} / \mathrm{min}$ vs $3.7 \pm 0.3 \mathrm{~L} / \mathrm{min}$, difference not significant), mixed venous oxygen saturation $(69.6 \% \pm 1.9 \%$ vs $69.6 \% \pm$ $5.2 \%$, difference not significant), central venous pressure (12.5 \pm $0.4 \mathrm{~mm} \mathrm{Hg}$ vs $11.4 \pm 1.0 \mathrm{~mm} \mathrm{Hg}$, difference not significant), mean pulmonary arterial pressure $(25.3 \pm 0.9 \mathrm{~mm} \mathrm{Hg}$ vs $24.4 \pm$ $1.5 \mathrm{~mm} \mathrm{Hg}$, difference not significant), heart rate $(85.3 \pm 11.6$ beats/min vs $87.4 \pm 3.6$ beats $/ \mathrm{min}$, difference not significant), or mean arterial pressure $(78.8 \pm 5.2 \mathrm{~mm} \mathrm{Hg}$ vs $76.4 \pm 5.7 \mathrm{~mm} \mathrm{Hg}$, difference not significant). The animals were randomly assigned to undergo either sham operation (thoracotomy alone) or TMR. The animals in the sham group $(\mathrm{n}=11)$ were then closed and allowed to recover. The TMR subset $(n=14)$ underwent revascularization with a SolarGen 2100s Ho:YAG TMR laser with a SoloGrip III handpiece (Cardiogenesis Corporation, Irvine, Calif). A total of 12 TMR channels (8-10 pulses/channel) at a density of $1 / \mathrm{cm}^{2}$ were created in the ischemic lateral wall. The Ho:YAG laser generates a $2.1-\mu \mathrm{m}$ wavelength with a $200-\mu$ s pulse width (repetition rate $5 \mathrm{~Hz}$, nominal power $7 \mathrm{~W} /$ channel, $1.4 \mathrm{~J} /$ pulse). The laser was used at the same settings and with the same technique that are used clinically and have been experimentally confirmed. ${ }^{3,4,15-17}$ A combination of change in pitch of the laser and a jet of blood from the channel after TMR confirmed the creation of transmural channels.

There are three major lasers available for TMR, the carbon dioxide, Ho:YAG, and xenon-chloride excimer lasers. The excimer laser, a cold, ultraviolet laser that creates channels by dissociation of molecular bonds, is not used clinically in the United States. The carbon dioxide and Ho:YAG lasers are infrared lasers that use thermal ablation to create channels. The Ho:YAG lasers pulsed thermoacoustic energy wave penetrates the tissue wider than does the single-pulse high-powered carbon dioxide laser. The degree of neovascularization after TMR has been shown to directly correlate with the degree of laser-induced tissue inflammation.

Eight weeks after initial surgery, the animals were anesthetized, and a continuous cardiac output pulmonary arterial catheter and an arterial line were placed. The heart was exposed through a median sternotomy. The aortopulmonary window was dissected free, and an ascending aortic flow probe (Transonic Systems, Inc, Ithaca, NY) was placed to measure cardiac output. The flow probe uses 
a Doppler measure of flow and as such provides a more accurate measure of cardiac output than does a pulmonary arterial catheter. Regional wall motion was analyzed with epicardial echocardiography. The animals were then euthanized for molecular analysis. Not all assays could be performed on all animals because of methodologic constraints between assays (lectin angiography prevented hemodynamic, Western blot, and immunocytochemical analyses). Eight of 25 animals did not have hemodynamic measurements.

\section{Flow Cytometric Analysis of Circulating EPC Upregulation}

Flow cytometric analysis was performed to evaluate upregulation of circulating EPCs, the precursor cells purportedly responsible for vasculogenesis. Forty-eight hours after either sham operation or therapy with the TMR procedure, circulating blood was obtained from the innominate vein. Red blood cell lysis was performed with standard ammonium chloride lysis buffer. Cell viability was assessed with 7-amino-actinomycin D (BD Biosciences, Franklin Lakes, NJ) labeling. Circulating lymphocytes were labeled with fluorescein isothiocyanate-conjugated anti-CD31 (Serotec, Raleigh, NC), phycoerythrin-conjugated anti-CD133 (Miltenyi Biotec Inc, Auburn, Calif), and allophycocyanin-conjugated anti-vascular endothelial growth factor (VEGF) receptor 2 (BD Biosciences) antibodies. Appropriate lymphocyte compensation controls were used. EPCs were defined as CD $31^{-} \mathrm{CD} 133^{+}$VEGFR2 ${ }^{+}$cells. Analysis ( $n=2$ /group) was performed on 2 million cells per group (FACS Calibur; BD Biosciences). EPC density is expressed as percentage of circulating lymphocytes. ${ }^{18-21}$

\section{Analysis of Myocardial Chemokine Expression}

Nuclear factor $\kappa \mathrm{B}(\mathrm{NF} \kappa \mathrm{B})$ plays a key role in stimulating vasculogenic mediators (VEGF, basic fibroblast growth factor), enhancing vasculogenesis, and inducing key vasculogenic transcription factors. $^{22-25}$ Angiopoietin 1, acting through the TIE2 receptor, stimulates vasculogenesis and enhances stabilization and maturation of vessels. ${ }^{26,27}$ We have sought to investigate alterations in these proangiogenic transcription factors and proteins to elucidate the mechanism of TMR. Myocardial sections were isolated from the ischemic territory of the left ventricle of both control and TMR group animals and homogenized with a mortar and pestle for protein extraction. Homogenized myocardial samples were suspended in Tissue Protein Extraction Reagent (Pierce Chemical Company, Rockford, Ill) with $1 \%$ Triton X-100 (The Dow Chemical Company, Midland, Mich), protease inhibitors (Pierce), and phosphatase inhibitors (Pierce). Protein concentrations were determined with the BioRad protein assay (Bio-Rad Laboratories) in triplicate. Myocardial protein $(50 \mu \mathrm{g} / \mathrm{sample})$ was loaded on precast $4 \%$ to $12 \%$ 1,3-bis(tris[hydroxymethyl]methylamino)propane gels after denaturation in reducing sample buffer. Proteins were transferred to $0.2 \mu \mathrm{m}$ polyvinylidene difluoride membranes (Invitrogen Corporation, Carlsbad, Calif) and subsequently blocked with 5\% nonfat dry milk in tris(hydroxymethyl)aminomethane-buffered saline solution. Immunoblotting was performed with antibodies against either $\mathrm{NF} \kappa \mathrm{B}$ (Abcam Inc, Cambridge, Mass) or angiopoietin 1 (Abcam). Labeling for actin (Abcam) confirmed equivalent loading of protein in control and TMR groups $(2510 \pm 172$ intensity units [iu] vs $2398 \pm 158 \mathrm{iu}$, difference not significant). Protein levels were quantified with Scion Image software v.4.0.3.2 (Scion Corporation, Frederick, Md).

\section{Quantification of Myocardial Angiogenesis}

Myocardial vascular density was determined by labeling the myocardial regions of the left circumflex territory for CD31, which is found on mature, differentiated endothelial cells of vasculature. Myocardial sections were fixed with acetone and blocked with $1 \%$ bovine serum albumin and $10 \%$ normal goat serum. The sections were treated overnight at $4{ }^{\circ} \mathrm{C}$ with mouse antirat CD31 antibody (BD PharMingen, San Diego, Calif). Samples were washed and incubated with goat antimouse fluorescein isothiocyanate-conjugated antibody (Abcam) for 1 hour at room temperature. Immunocytochemical vascular density analysis was performed in four fields for each sample for remote and ischemic myocardium $(20 \times$, Leica DM5000B microscope, Leica Application Suite v2.2.0; Leica Microsystems Inc, Deerfield, Ill).

\section{Assessment of Myocardial Perfusion}

Before each animal was euthanized, $500-\mu \mathrm{g} / \mathrm{kg}$ fluorescein-labeled Lycopersicon esculentum (tomato) lectin (Vector Laboratories, Inc, Burlingame, Calif) was injected into the superior vena cava and allowed to circulate for 10 minutes. Tomato lectin binds to the surface $\mathrm{N}$-acetylglucosamine oligomers of endothelial cells lining perfused vessels. ${ }^{28}$ Direct contact of lectin with endothelial cells is requisite for lectin labeling, so only perfused vessels are labeled.

After lectin perfusion, the hearts were explanted and snap frozen in liquid nitrogen. Sequential sections were obtained with scanning laser confocal microscopy through $100-\mu$ m thick myocardial sections of normal, remote, and ischemic myocardial regions. ${ }^{29}$ Three-dimensional reconstructions of the image stacks were created with Volocity Software v.3.61 (Improvision Inc, Waltham, Mass). Pixels delineating labeled vasculature and total tissue sections were quantified, thereby allowing determination of total perfusion per mass of myocardial tissue. Quantitation of the lectin-bound vasculature thus provided a direct measure of myocardial perfusion in the form of a microvascular angiogram. Measurements were made in two myocardial regions for each sample.

\section{Assessment of Myocardial Viability}

Analysis of myocardial viability was performed by quantifying myocardial density. Myocardial thin sections $(10 \mu \mathrm{m})$ were counterstained with Masson trichrome stain to delineate myofilament structure and function. Myofilament density (total cardiomyocytes/high-power field [hpf]) was determined in five separate ischemic myocardial regions in a $20 \times \mathrm{hpf}$ as a measure of myocardial density. ${ }^{29,30}$

\section{Quantification of Myocardial Function}

Myocardial regional contractile function was assessed with echocardiography (Phillips Sonos $5500 \mathrm{rev}$ D, $8 \mathrm{MHz}, 6 \mathrm{~cm}$; Philips Medical Systems North America, Shelton, Conn) 8 weeks after ameroid placement. Wall motion score index was analyzed according to the American Society of Echocardiography regional wall motion grading scale ( 1 normal, 2 hypokinetic, 3 akinetic, 4 dyskinetic, 5 aneurysmal), whereby six regions were scored at the basal and midpapillary level with parasternal short-axis views. The apex was scored with parasternal long-axis visualization. Global wall motion score index was determined by the average of the 13 segments analyzed. The hemodynamic benefits after therapy with TMR would be expected to be largely regional in nature. Therefore careful 
attention was focused on analysis of regional myocardial contractility with epicardial echocardiography of the ischemic lateral wall. Regional contractility of the lateral wall was determined at the midpapillary level with imaging along the short axis. Invasive hemodynamic analysis was determined by continuous cardiac output pulmonary arterial catheter, a femoral arterial catheter, and an ascending aortic flow probe (Transonic) placed around the aortic root for Doppler analysis of cardiac output.

\section{Data Analysis}

Quantitative data are expressed as mean \pm SEM. Statistical significance was evaluated with the unpaired Student $t$ test for comparison between two means.

\section{Results}

Upregulation of Circulating EPCs

Flow cytometric analysis demonstrated a significant increase in the circulating $\mathrm{CD} 1^{-} \mathrm{CD}^{-} 33^{+} \mathrm{VEGFR}^{+}{ }^{+} \mathrm{EPC}$ density 48 hours after therapy with TMR relative to sham control values $(0.046 \% \pm 0.02 \%$ total lymphocytes vs $0.017 \% \pm$ $0.007 \%$ total lymphocytes, $\mathrm{n}=2$ /group]. By gating for the $\mathrm{CD}^{-}$subpopulation, we selected for the immature, pluripotent EPC population. Viability analysis with 7amino-actinomycin D demonstrated minimal cell death. Representative histogram and dot plots used in EPC identification are demonstrated in Figure 1.

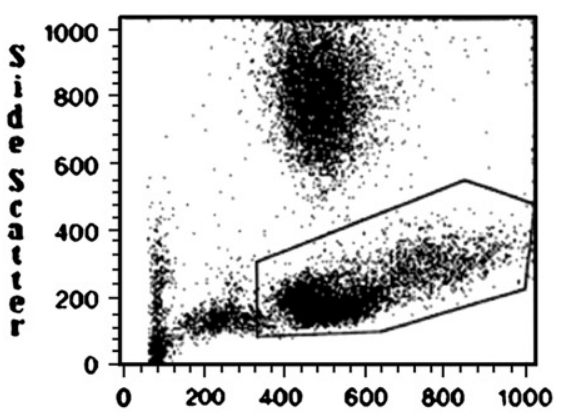

A Fonward Scatter

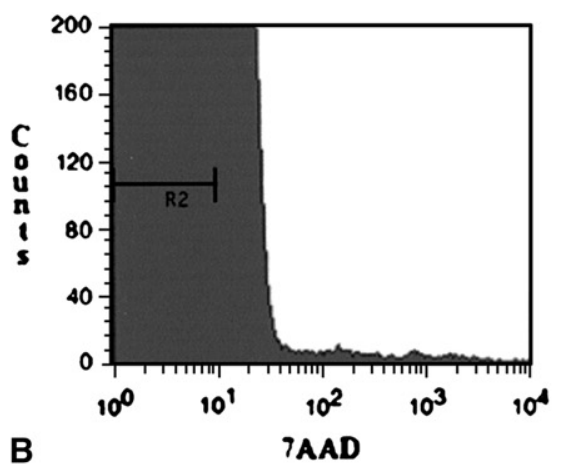

B

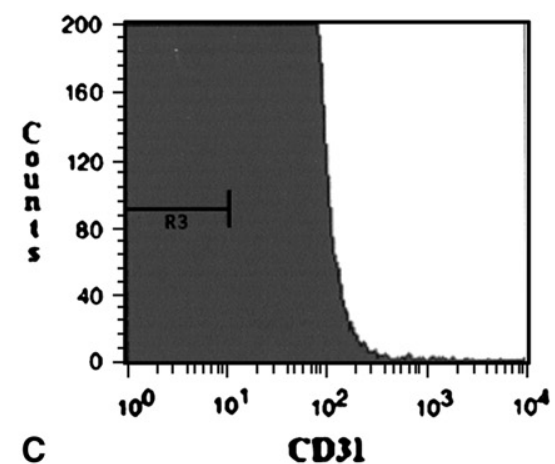

C

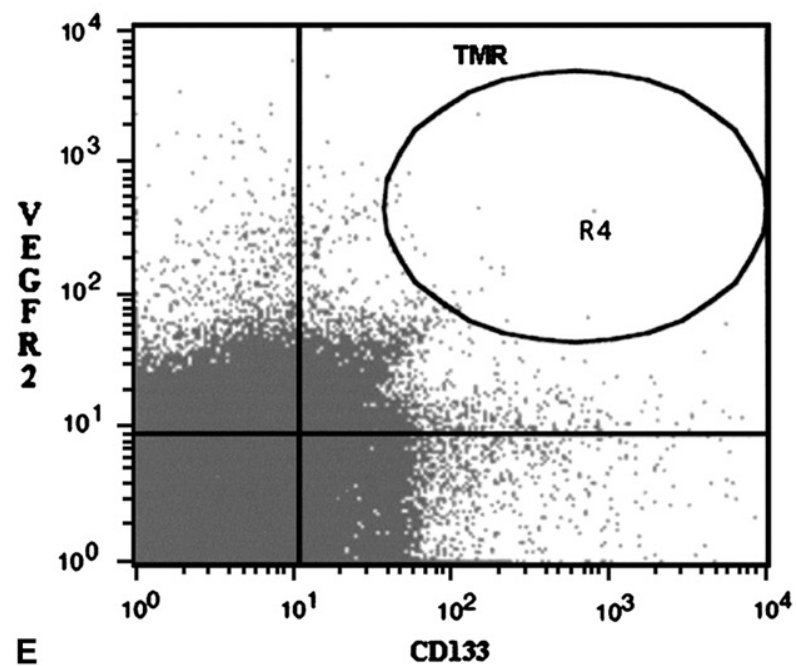

E

CD133

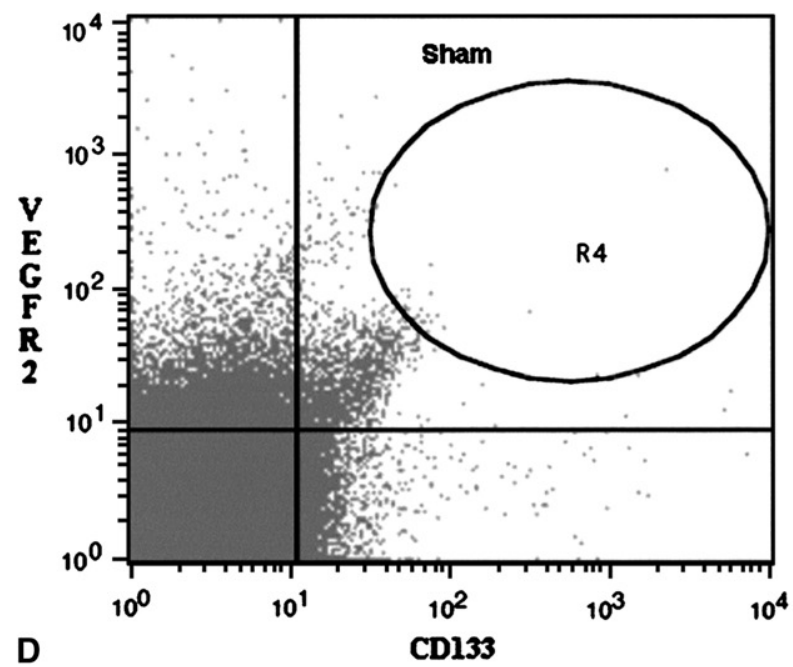

Figure 1. Therapy with transmyocardial laser revascularization upregulates circulating CD31 $^{-}$CD133 $^{+}$VEGFR2 $^{+}$ endothelial progenitor cells. Representative flow cytometric plots of circulating blood 48 hours after either sham treatment (thoracotomy alone) or transmyocardial laser revascularization. A, Dot plots of forward and side scatter determination of lymphocyte subpopulation; representative gate for lymphocytes is visualized. B, Histogram of 7amino-actinomycin D (7AAD) labeling of lymphocyte cell viability. C, Histogram representing a CD31 $^{-}$population. Representative, gated viable, $C D 31^{-}$cell population is delineated. D and E, EPC density in representative animals from sham (D) and transmyocardial laser revascularization (E) groups after gating for CD31- population, as determined by colabeling of CD133 and VEGFR2. Quantification of endothelial progenitor cell density demonstrates significant increase relative to sham control in circulating $\mathrm{CD}^{-}{ }^{-} \mathrm{CD} 33^{+}{ }^{\text {VEGFR2 }}{ }^{+}$endothelial progenitor cells after transmyocardial laser revascularization. 


\section{Upregulation of Cytokines with TMR}

Protein quantification with Western blot analysis demonstrated a statistically significant increase in myocardial expression of $\mathrm{NF} \kappa \mathrm{B}$ after TMR relative to control (42 \pm 27 iu vs $591 \pm 383 \mathrm{iu}, \mathrm{n}=4 / \mathrm{sham}, \mathrm{n}=6 / \mathrm{TMR}, P=.03)$. Western blotting demonstrated a dramatic increase in expression of $\mathrm{NF} \kappa \mathrm{B}$ within the TMR-treated hibernating myocardium (Figure 2). This increase in the provasculogenic protein $\mathrm{NF} \kappa \mathrm{B}$ implies a neovasculogenic effect of TMR.

Similarly, dramatic increases from control values in expressions of both the native angiopoietin $1(0 \pm 0$ iu vs $241 \pm 87 \mathrm{iu}, \mathrm{n}=4 /$ sham, $\mathrm{n}=6 / \mathrm{TMR}, P=.003)$ and glycosylated angiopoietin $1(460 \pm 194 \mathrm{iu}$ vs $1394 \pm 436 \mathrm{iu}, \mathrm{n}=4$ / sham, $\mathrm{n}=6 / \mathrm{TMR}, P=.003$ ) proteins were detected in the hibernating myocardium after TMR. As with $\mathrm{NF}_{\kappa} \mathrm{B}$, there was a dramatic increase in angiopoietin 1 expression in the TMR group visible on the Western blot (Figure 2). Enhanced expression of angiopoietin 1 provides an indication of vasculogenesis, vascular maturation, and increased myocardial viability.

\section{TMR Enhancement of Myocardial Angiogenesis}

Analysis of myocardial vascular density demonstrated a statistically significant increase in vasculature within the

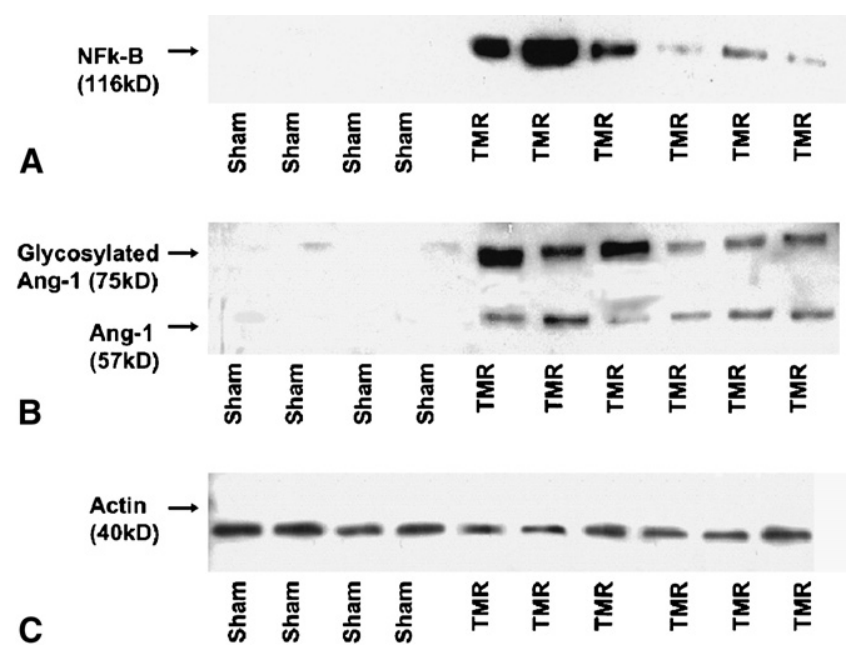

Figure 2. A, Western blot analysis of nuclear factor $\kappa$ B (NFk-B) myocardial protein levels in sham and transmyocardial laser revascularization (TMR) groups reveals dramatic upregulation after TMR in hibernating myocardium. Nuclear factor $\kappa B$ was detected at $116 \mathrm{kDa}$. B, Western blot analysis of angiopoietin 1 (Ang-1) expression in hibernating myocardium in sham and transmyocardial laser revascularization groups demonstrates marked increase in angiopoietin 1 after transmyocardial laser revascularization. Expression at $57 \mathrm{kDa}$ corresponds to native angiopoietin 1, whereas 75-kDa band demonstrates expression of highly glycosylated form of angiopoietin 1. Glycosylated angiopoietin 1 protein plays vital role in vascular maturation. C, Western blot analysis of actin in sham and transmyocardial laser revascularization groups confirms equivalent protein loading. territory of the ischemic myocardium 4 weeks after TMR $(18.8 \pm 8.7$ vessels/hpf vs $31.4 \pm 10.2$ vessels/hpf, $\mathrm{n}=8 /$ group, $P=.02$ ). The enhanced vascular density correlated with an increase in the circulating EPC population, implying EPC-meditated vasculogenesis. On the other hand, it is possible that the enhanced vascularity was a manifestation of the sprouting of new vasculature from preexisting blood vessels. There was no difference in remote myocardial vascular density between control and TMR groups, demonstrating equivalent baseline myocardial structure $(60.9 \pm 2.1$ vessels/hpf vs $60.3 \pm 2.9$ vessels/hpf, difference not significant, $\mathrm{n}=8$ ). Representative images demonstrating immunofluorescent $\mathrm{CD} 31^{+}$-labeled vasculature within the ischemic myocardial territory are shown in Figure E1.

\section{Augmented Myocardial Perfusion After TMR}

Confocal microscopy allowed imaging of myocardial sections perfused with tomato lectin. Fluorescein-conjugated lectin exclusively labels perfused vasculature. Therefore a microvascular angiogram of only perfused vasculature is obtained with this method. Analysis of remote myocardial vasculature did not reveal a difference in myocardial perfusion between sham $(\mathrm{n}=2)$ and TMR $(\mathrm{n}=3)$ groups $(0.064 \pm$ $0.008 \mu \mathrm{m}^{3}$ blood $/ \mu \mathrm{m}^{3}$ tissue vs $0.057 \pm 0.001 \mu \mathrm{m}^{3}$ blood/ $\mu \mathrm{m}^{3}$ tissue, difference not significant). This served as an internal control, validating the assay and demonstrating similar baseline perfusions in the two groups.

Qualitative analysis revealed a visually apparent increase in hibernating myocardial perfusion after TMR (Figure 3). Three-dimensional quantitative analysis of myocardial perfusion within the hibernating myocardium demonstrated a statistically significant increase in myocardial perfusion after TMR $(\mathrm{n}=2)$ relative to the sham control group $(\mathrm{n}=3,0.044 \pm$ $0.004 \mu \mathrm{m}^{3}$ blood $/ \mu \mathrm{m}^{3}$ tissue vs $0.028 \pm 0.009 \mu \mathrm{m}^{3}$ blood/ $\mu \mathrm{m}^{3}$ tissue, $P=.01$ ). In addition to demonstrating an increase in perfusion following TMR, these data confirm the increase in vasculature that was noted with CD31 vascular labeling.

The literature is inconclusive regarding changes in perfusion after therapy with TMR. A lack of consistent improvement in perfusion in the published literature may be due to differences in therapeutic strategy, timing of measurement, and sensitivity in measuring perfusion. Our study demonstrated a nearly $50 \%$ increase in perfusion after TMR. As is proved in this study, lectin angiography is a highly sensitive measure that is capable of measuring changes in perfusion at the microvascular level. Quantification of perfusion with microspheres after TMR with a carbon dioxide laser has also demonstrated a dramatic increase in perfusion, corroborating these findings. ${ }^{31}$

\section{Enhanced Myocardial Viability After TMR}

Qualitative analysis of myocardial sections demonstrated a significant increase in myocardial viability after TMR (Figure 4). Quantitative analysis demonstrated a statistically 


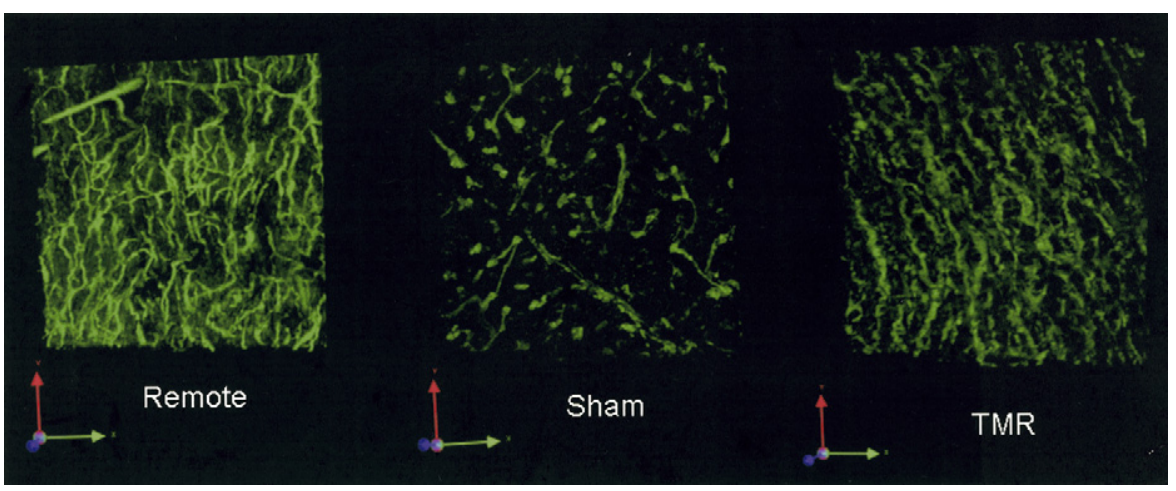

Figure 3. Three-dimensional microvascular lectin angiogram demonstrates enhanced myocardial perfusion after therapy with transmyocardial laser revascularization (TMR). Representative angiograms from remote myocardium and ischemic myocardium from animals in sham and transmyocardial laser revascularization groups are presented (z-series, $25 \times$ oil magnification, Zeiss LSM-510 Meta Confocal Microscope; Carl Zeiss, Inc, Thornwood, NY). There was no difference in remote myocardial perfusion between sham and transmyo-

cardial laser revascularization groups. Perfusion of the ischemic myocardium was significantly increased after transmyocardial laser revascularization. Orientation is presented in lower left corners. Red indicates y-axis; green indicates x-axis; blue indicates z-axis.

significant increase in myofilament density in the hibernating myocardium after TMR relative to the control group (50.8 \pm 7.5 myofilaments/hpf vs $40.7 \pm 8.5$ myofilaments/hpf, $\mathrm{n}=8$ /group, $P=.03$ ). Preservation of myocardium correlated with increases in myocardial $\mathrm{NF}_{\kappa} \mathrm{B}$ and angiopoietin 1 protein, in vasculature, and in perfusion.

\section{TMR Improvement of Myocardial Function}

Assessment of myocardial function demonstrated a statistically significant increase in hemodynamic function after therapy with TMR relative to the sham group (Table 1). There were marked improvements in both cardiac output and mixed venous oxygen saturation after therapy. Moreover, there were no differences in preload, afterload, heart rate, or hemoglobin level.

TMR is regionally targeted to the ischemic myocardium, rather than globally to the entire myocardial surface. As such, one would expect the most significant improvements in myocardial contractility to occur focally. Echocardiography provides a means of studying regional myocardial function. Myocardial contractile analysis demonstrated a significant improvement in contractility of the ischemic lateral wall of the left ventricle after TMR. Moreover, improvements in global myocardial function were evidenced by significant improvements in the global wall motion score index.

\section{Discussion}

In this study, we demonstrated an increase in circulating EPCs shortly after TMR. EPCs have the potential to differentiate into endothelial cells and the support network necessary for mature myocardial vasculature. ${ }^{18,32}$ They are stimulated by several factors, including trauma, ischemia, and chemokines. $\mathrm{NF}_{\kappa} \mathrm{B}$ is a potent chemokine and transcription factor that induces vasculogenesis. ${ }^{22-25}$ We have shown a dramatic increase in $\mathrm{NF} \kappa \mathrm{B}$ levels after TMR, whereas this factor was nearly absent in the sham subset. This increase in $\mathrm{NF} \kappa \mathrm{B}$ levels may play a key role in targeting EPCs to the ischemic myocardium, thereby enhancing EPC mediated vasculogenesis and perfusion. In human clinical trials, exogenous administration of cultured EPCs has led to enhanced myocardial perfusion, illustrating the role of EPCs in enhancing myocardial blood flow. ${ }^{33-35}$

We also demonstrated an increase in angiopoietin 1 expression that correlated with increased vasculogenesis and perfusion. Like the other TMR-upregulated proteins (VEGF, basic fibroblast growth factor, and transforming growth factor $\beta$ ), angiopoietin 1 may play a key role in increasing myocardial perfusion and stimulating vascular maturation after TMR. Myocardial angiopoietin 1 overexpression after acute myocardial infarction has been associated with increased myocardial survival, limited ventricular remodeling,
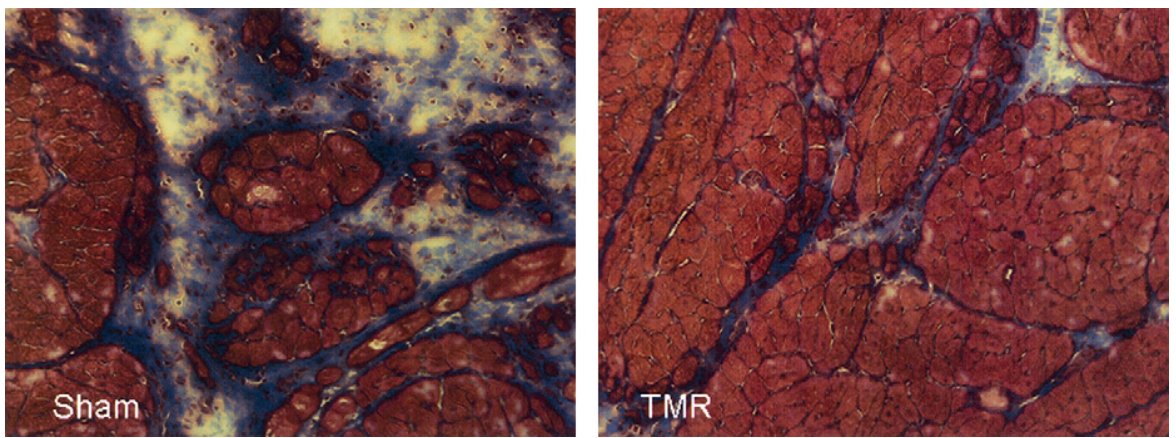

Figure 4. Representative Masson trichrome-stained images of myofilament density within an ischemic territory of the left circumflex coronary artery of myocardium from sham and transmyocardial laser revascularization (TMR) Groups demonstrating enhanced myofilament density in latter (original magnification $20 \times$ ). Red indicates muscle; blue indicates collagen; black indicates nuclei. 
TABLE 1. Hemodynamic parameters 4 weeks after sham thoracotomy or transmyocardial laser revascularization therapy of ischemic myocardium in the left circumflex coronary artery territory

\begin{tabular}{|c|c|c|c|}
\hline & Sham $(n=8)$ & $\operatorname{TMR}(n=9)$ & $P$ value \\
\hline Heart rate (beats/min) & $89.1 \pm 5.3$ & $84.1 \pm 5.8$ & NS \\
\hline $\begin{array}{l}\text { Central venous } \\
\text { pressure }(\mathrm{mm} \mathrm{Hg})\end{array}$ & $11.0 \pm 0.8$ & $11.5 \pm 0.9$ & NS \\
\hline $\begin{array}{l}\text { Mean pulmonary } \\
\text { arterial pressure } \\
(\mathrm{mm} \mathrm{Hg})\end{array}$ & $21.0 \pm 2.1$ & $22.5 \pm 1.1$ & NS \\
\hline $\begin{array}{l}\text { Mean arterial pressure } \\
(\mathrm{mm} \mathrm{Hg})\end{array}$ & $83.5 \pm 7.4$ & $78.5 \pm 8.6$ & NS \\
\hline Cardiac output (L/min) & $2.1 \pm 0.2$ & $2.7 \pm 0.2$ & .007 \\
\hline Hemoglobin ( $g / d L)$ & $8.7 \pm 0.9$ & $8.5 \pm 0.9$ & NS \\
\hline $\begin{array}{l}\text { Mixed venous oxygen } \\
\text { saturation }(\%)\end{array}$ & $64.7 \pm 3.6$ & $76.1 \pm 3.4$ & .008 \\
\hline $\begin{array}{l}\text { American Society of } \\
\text { Echocardiography } \\
\text { wall motion score } \\
\text { index }^{*}\end{array}$ & $1.5 \pm 0.2$ & $1.2 \pm 0.1$ & .01 \\
\hline $\begin{array}{l}\text { Echocardiographic } \\
\text { regional wall motion } \\
\text { score index, lateral } \\
\text { wall* }\end{array}$ & $2.1 \pm 0.2$ & $1.3 \pm 0.4$ & .009 \\
\hline
\end{tabular}

Values are mean \pm SEM. TMR, Transmyocardial laser revascularization; $N S$, not significant. *A normal motion value is scored as 1 .

and enhanced function. ${ }^{26,27}$ The improvements in cardiac function that result from TMR are likely a manifestation of enhanced perfusion and an attenuation of hypoxia, with resultant augmentation of myocardial viability.

As evidenced in this study, there is a marked and statistically significant preservation of myofilament mass after therapy with TMR. The preservation of muscle mass directly correlates with an increase in perfusion. Numerous studies have demonstrated that myocardial ischemia mediates abnormal cardiomyocyte metabolism, decoupling of energy consumption and work generation, and enhanced apoptosis. Ischemic myocardium receives limited perfusion, resulting in limited contractility and increased propensity toward cell death. By augmenting perfusion, we are enhancing viability and the functional work that the muscle is able to perform. In light of the tenuous viability of the ischemic myocardium it is certainly possible that only moderate increases in perfusion are required for dramatic increases in function. Restoration of myocardial perfusion and reversal of ischemia, as is seen experimentally in this study with TMR, play a critical role in preserving myofilament density, in ventricular remodeling, and ultimately in maintaining myocardial function.

Clinical evidence for the protective effects of laser revascularization has also been demonstrated. The largest randomized, multicenter, prospective study compared TMR with a Ho:YAG laser with medical management alone for patients with class IV angina. This study demonstrated reduction in angina, improved exercise tolerance, and greater freedom from cardiac events with TMR. ${ }^{4}$ Similarly, Frazier and colleagues ${ }^{5}$ reported a statistically significant improvement in perfusion and a decrease in hospitalization after TMR with a carbon dioxide laser relative to medical therapy.

There remains some controversy regarding the molecular mechanism behind TMR's success. Proposed alternate theories for the clinical improvements after TMR include placebo effect, myocardial denervation, and local trauma. ${ }^{36,37} \mathrm{Im}-$ provements in perfusion that have been noted after TMR suggest reversal of ischemia rather than denervation as the major mediator of improved cardiac function. Histologic studies 6 months after TMR have demonstrated regeneration of the myocardial sympathetic nerves. Physiologic assays evaluating efferent nerve conduction have demonstrated intact conduction after TMR, refuting denervation. ${ }^{38,39}$ Studies evaluating laser TMR versus mechanical TMR have demonstrated improvements in arteriogenesis and function only after laser TMR, showing an effect with laser energy beyond mechanical trauma. ${ }^{15,40}$

The body of literature on TMR has included a combination of carbon dioxide and Ho:YAG lasers. These studies are not directly comparable. There is, however, a correlation between the two lasers in terms of beneficial improvements in angiogenesis, myocardial perfusion, and function. The improvements noted with these lasers may be related to induction of inflammation to varying degrees. ${ }^{40}$ Although not directly comparable, these studies thus can be used for global assessment of changes in molecular pathways and cellular physiology after laser revascularization.

Combining clinical data with our mechanistic findings, beginning with the analysis of acute effects on a molecular level, providing insight into the findings of enhanced vasculogenesis, perfusion, viability, and function after TMR, provides strong evidence to support TMR to treat myocardial ischemia not amenable to coronary artery bypass grafting or percutaneous coronary intervention. In the setting of isolated TMR, therapy may be administered by robotic or thoracoscopic $^{41}$ means, thereby reducing postprocedure recovery. In the future, the combination of TMR with either EPC or cytokine delivery (stromal cell-derived factor $1 \alpha$, VEGF, basic fibroblast growth factor) may provide a robust EPC-mediated vasculogenic signal to enhance perfusion further and reverse ischemia.

\section{References}

1. Rosamond W, Flegal K, Friday G, Furie K, Go A, Greenlund K, et al. Heart disease and stroke statistics-2007 update: a report from the American Heart Association Statistics Committee and Stroke Statistics Subcommittee. Circulation. 2007;115:e69-171.

2. Kohmoto T, Argenziano M, Yamamoto N, Vliet KA, Gu A, DeRosa CM, et al. Assessment of transmyocardial perfusion in alligator hearts. Circulation. 1997;95:1585-91.

3. Allen KB, Dowling RD, Schuch DR, Pfeffer TA, Marra S, Lefrak EA, et al. Adjunctive transmyocardial revascularization: five-year 
follow-up of a prospective, randomized trial. Ann Thorac Surg. 2004;78: $458-65$.

4. Allen KB, Dowling RD, Fudge TL, Schoettle GP, Selinger SL, Gangahar DM, et al. Comparison of transmyocardial revascularization with medical therapy in patients with refractory angina. $N$ Engl J Med. 1999;341:1029-36.

5. Frazier OH, March RJ, Horvath KA. Transmyocardial revascularization with a carbon dioxide laser in patients with end-stage coronary artery disease. N Engl J Med. 1999;341:1021-8.

6. Burkhoff D, Schmidt S, Schulman SP, Myers J, Resar J, Becker LC, et al. Transmyocardial laser revascularisation compared with continued medical therapy for treatment of refractory angina pectoris: a prospective randomised trial. ATLANTIC Investigators. Angina Treatments-Lasers and Normal Therapies in Comparison. Lancet. 1999;354:885-90.

7. Horvath KA, Aranki SF, Cohn LH, March RJ, Frazier OH, Kadipasaoglu KA, et al. Sustained angina relief 5 years after transmyocardial laser revascularization with a $\mathrm{CO}_{2}$ laser. Circulation. 2001; 104(12 Suppl 1):I81-4.

8. Bridges CR, Horvath KA, Nugent WC, Shahian DM, Haan CK, Shemin RJ, et al. The Society of Thoracic Surgeons practice guideline series: transmyocardial laser revascularization. Ann Thorac Surg. 2004;77:1494-502.

9. Kohmoto T, Fisher PE, Gu A, Zhu SM, Yano OJ, Spotnitz HM, et al. Does blood flow through holmium:YAG transmyocardial laser channels? Ann Thorac Surg. 1996;61:861-8.

10. Wadia Y, Khaki A, Kajitani M, Mori Y, Irvine T, Sahn D, et al. Effects of transmyocardial laser revascularization by using a prototype pulsed $\mathrm{CO}_{2}$ laser on contractility and perfusion of chronically ischemic myocardium in a porcine model. ASAIO J. 2000;46:786-91.

11. Kohmoto T, Fisher PE, Gu A, Zhu SM, DeRosa CM, Smith CR, et al. Physiology, histology, and 2-week morphology of acute transmyocardial channels made with a $\mathrm{CO}_{2}$ laser. Ann Thorac Surg. 1997;63: 1275-83.

12. O'Konski MS, White FC, Longhurst J, Roth D, Bloor CM. Ameroid constriction of the proximal left circumflex coronary artery in swine. A model of limited coronary collateral circulation. Am J Cardiovasc Pathol. 1987;1:69-77.

13. Hamawy AH, Lee LY, Samy SA, Polce DR, Szulc M, Vazquez M, et al. Transmyocardial laser revascularization dose response: enhanced perfusion in a porcine ischemia model as a function of channel density. Ann Thorac Surg. 2001;72:817-22.

14. Roth DM, Maruoka Y, Rogers J, White FC, Longhurst JC, Bloor CM. Development of coronary collateral circulation in left circumflex ameroid-occluded swine myocardium. Am J Physiol. 1987;253(5 Pt 2): H1279-88.

15. Hughes GC, Biswas SS, Yin B, Baklanov DV, Annex BH, Coleman RE, et al. A comparison of mechanical and laser transmyocardial revascularization for induction of angiogenesis and arteriogenesis in chronically ischemic myocardium. J Am Coll Cardiol. 2002;39:1220-8.

16. Hughes GC, Kypson AP, Annex BH, Yin B, St Louis JD, Biswas SS, et al. Induction of angiogenesis after TMR: a comparison of holmium:YAG, $\mathrm{CO}_{2}$, and excimer lasers. Ann Thorac Surg. 2000;70:504-9.

17. Allen KB, Dowling RD, DelRossi AJ, Realyvasques F, Lefrak EA, Pfeffer TA, et al. Transmyocardial laser revascularization combined with coronary artery bypass grafting: a multicenter, blinded, prospective, randomized, controlled trial. J Thorac Cardiovasc Surg. 2000;119: $540-9$.

18. Szmitko PE, Fedak PW, Weisel RD, Stewart DJ, Kutryk MJ, Verma S. Endothelial progenitor cells: new hope for a broken heart. Circulation. 2003;107:3093-100.

19. Peichev M, Naiyer AJ, Pereira D, Zhu Z, Lane WJ, Williams M, et al. Expression of VEGFR-2 and AC133 by circulating human CD34(+) cells identifies a population of functional endothelial precursors. Blood. 2000;95:952-8.

20. Hristov M, Erl W, Weber PC. Endothelial progenitor cells: mobilization, differentiation, and homing. Arterioscler Thromb Vasc Biol. 2003;23: $1185-9$.

21. Rothe G, Barlage S, Schmitz G, Kloushe M. Flow cytometric assessment of haematopoietic stem and progenitor cells. J Lab Med. 2003;27: $175-81$.
22. Tong Q, Zheng L, Lin L, Li B, Wang D, Huang C, et al. Participation of the PI-3K/Akt-NF-kappa B signaling pathways in hypoxia-induced mitogenic factor-stimulated Flk-1 expression in endothelial cells. Respir Res. 2006;7:101.

23. Sasaki H, Ray PS, Zhu L, Galang N, Maulik N. Oxidative stress due to hypoxia/reoxygenation induces angiogenic factor VEGF in adult rat myocardium: possible role of NFkappaB. Toxicology. 2000;155:27-35.

24. Sasaki H, Ray PS, Zhu L, Otani H, Asahara T, Maulik N. Hypoxia/reoxygenation promotes myocardial angiogenesis via an NF kappa B-dependent mechanism in a rat model of chronic myocardial infarction. $J \mathrm{Mol}$ Cell Cardiol. 2001;33:283-94.

25. Karin M. Nuclear factor-kappaB in cancer development and progression. Nature. 2006;441:431-6.

26. Takahashi K, Ito Y, Morikawa M, Kobune M, Huang J, Tsukamoto M, et al. Adenoviral-delivered angiopoietin-1 reduces the infarction and attenuates the progression of cardiac dysfunction in the rat model of acute myocardial infarction. Mol Ther. 2003;8:584-92.

27. Siddiqui AJ, Blomberg P, Wardell E, Hellgren I, Eskandarpour M, Islam KB, et al. Combination of angiopoietin-1 and vascular endothelial growth factor gene therapy enhances arteriogenesis in the ischemic myocardium. Biochem Biophys Res Comm. 2003;310:1002-9.

28. Gee MS, Procopio WN, Makonnen S, Feldman MD, Yeilding NM, Lee WM. Tumor vessel development and maturation impose limits on the effectiveness of anti-vascular therapy. Am J Pathol. 2003;162: 183-93.

29. Atluri P, Liao GP, Panlilio CM, Hsu VM, Leskowitz MJ, Morine KJ, et al. Neovasculogenic therapy to augment perfusion and preserve viability in ischemic cardiomyopathy. Ann Thorac Surg. 2006;81:1728-36.

30. Woo YJ, Panlilio CM, Cheng RK, Liao GP, Atluri P, Hsu VM, et al. Therapeutic delivery of cyclin $\mathrm{A}_{2}$ induces myocardial regeneration and enhances cardiac function in ischemic heart failure. Circulation. 2006;114(1 Suppl):I206-13.

31. Muhling OM, Wang Y, Jerosch-Herold M, Cayton MM, Wann LS, Mirhoseini MM, et al. Improved myocardial function after transmyocardial laser revascularization according to cine magnetic resonance in a porcine model. J Thorac Cardiovasc Surg. 2004;128:391-5.

32. Rafii S, Meeus S, Dias S, Hattori K, Heissig B, Shmelkov S, et al. Contribution of marrow-derived progenitors to vascular and cardiac regeneration. Semin Cell Dev Biol. 2002;13:61-7.

33. Assmus B, Schachinger V, Teupe C, Britten M, Lehmann R, Dobert N, et al. Transplantation of Progenitor Cells and Regeneration Enhancement in Acute Myocardial Infarction (TOPCARE-AMI). Circulation. 2002;106:3009-17.

34. Britten MB, Abolmaali ND, Assmus B, Lehmann R, Honold J, Schmitt J, et al. Infarct remodeling after intracoronary progenitor cell treatment in patients with acute myocardial infarction (TOPCAREAMI): mechanistic insights from serial contrast-enhanced magnetic resonance imaging. Circulation. 2003;108:2212-8.

35. Yeh ET, Zhang S, Wu HD, Korbling M, Willerson JT, Estrov Z. Transdifferentiation of human peripheral blood $\mathrm{CD} 34^{+}$-enriched cell population into cardiomyocytes, endothelial cells, and smooth muscle cells in vivo. Circulation. 2003;108:2070-3.

36. Asai T, Yamamoto S, Ishino K, Kohmoto T, Kuriyama M, Kato G, et al. Time-dependent regional myocardial denervation as a nonspecific response to transmyocardial laser revascularization. Ann Thorac Surg. 2005;80:1362-9.

37. Yamamoto N, Gu A, DeRosa CM, Shimizu J, Zwas DR, Smith CR, et al. Radio frequency transmyocardial revascularization enhances angiogenesis and causes myocardial denervation in canine model. Lasers Surg Med. 2000;27:18-28.

38. Hughes GC, Baklanov DV, Biswas SS, Pippen AM, DeGrado TR, Coleman RE, et al. Regional cardiac sympathetic innervation early and late after transmyocardial laser revascularization. J Card Surg. 2004;19:21-7.

39. Minisi AJ, Topaz O, Quinn MS, Mohanty LB. Cardiac nociceptive reflexes after transmyocardial laser revascularization: implications for the neural hypothesis of angina relief. $J$ Thorac Cardiovasc Surg. 2001;122:712-9.

40. Mouli SK, Fronza J, Greene R, Robert ES, Horvath KA. What is the optimal channel density for transmyocardial laser revascularization? Ann Thorac Surg. 2004;78:1326-31. 
41. Allen GS. Mid-term results after thoracoscopic transmyocardial laser revascularization. Ann Thorac Surg. 2005;80:553-8.

\section{Discussion}

Dr Frank W. Sellke (Boston, Mass). TMR was found several years ago to improve perfusion and function in animals, yet most clinical trials have had negative or barely positive results. Do you think you are comparing TMR with no TMR in a clinically relevant model? We don't do TMR on patients that don't have coronary disease or hypercholesterolemia or other risk factors for vascular disease. Would you have seen the same changes had you used a model with endothelial dysfunction and vascular disease?

Dr Atluri. I believe we would have. The goal in this study is that we were trying to create a region of myocardial ischemia, a true region of myocardial hypocontractility. I think the key is that we are looking at regional dysfunction within our area of interest. Yes, therapy did create a difference in this model. What we were basically trying to replicate is not necessarily the global dysfunction but the regional contractile dysfunction and malperfusion that we are trying to treat. In human beings, there may be an entire left ventricular region with endothelial dysfunction and arteriosclerosis, compromising the entire wall. What we are trying to do is replicate dysfunction in just one region in which the ameroid is placed. We focused our studies on studying this area and also on studying the regional hemodynamic benefits.

Dr Keith B. Allen (Indianapolis, Ind). This was an elegant presentation, and I enjoyed it. You have shown microvascular improvement at the cellular level. I think this explains some of the clinical findings with regard to the last question, where insensitive tests such as thallium have been used previously to detect improvement in perfusion. With a $12 \%$ to $15 \%$ error rate, it is easy to see why changes at the cellular level may not necessarily be detected. You have nicely demonstrated with DNA and cellular analysis that TMR serves as a biomechanical trigger, with upregulation of the myocytes surrounding the border zone of the laser channel. We have hypothesized that this is a fertile area for enhanced angiogenesis by the addition of biologic materials, either PRP, stem cells, or things like VEGF and basic fibroblast growth factor. Do you have plans to carry on further studies looking at that possibility?

Dr Atluri. We thought this as sort of a two-step process. First, is TMR usable? I think we have evidence that it is in fact usable. I have enjoyed reading your articles in the past, and clearly I know that you believe in the utility of TMR.
I believe the process behind TMR, as you elucidated, is probably related to inflammation. In this study, inflammation without gross tissue destruction has been evidenced. For example, you double TMR channels from 1 to 2 channels $/ \mathrm{cm}^{2}$, you get too much destruction; decrease it, and you don't have enough inflammation for therapy. The moment you have inflammation, you upregulate cytokines and DNA transcription factors. After that, you get enhanced microvascular perfusion, which is the key. It is not the development of the large vessels or the big highways but rather the small microvasculature that enhances perfusion.

The other way to augment that perfusion in addition to upregulating the body's own reparative system is to enhance angiogenesis with either additional cytokines or cell transplantation. We are looking into these adjunctive therapies as sort of a second stage of investigation.

Dr Frank Bowen (Boston, Mass). I have two questions. First, did you find in the animals that underwent TMR that there was preservation of global systolic function in terms of preserving left ventricular end-systolic and end-diastolic volumes, leading to increased cardiac output and global function? Second, given that there are different energy sources with TMR, do you think that there will be a difference between a carbon dioxide laser and a Ho:YAG laser?

Dr Atluri. That was the big question we had to answer in deciding on a laser. The three lasers to choose from were the excimer laser, the carbon dioxide laser, and the Ho:YAG laser. The excimer laser is not commercially available in the United States, although it is used in Europe. Dr Hughes in Journal of the American College of Cardiology back in 2002 presented his results in which he basically found no difference between the excimer laser and sham treatment in terms of angiogenesis or vascular density. The next decision was between carbon dioxide and Ho:YAG. Dr Horvath in 2004 published some of these results. The difference between a Ho:YAG laser and carbon dioxide laser was marginal; nonetheless, there was enhanced vascularity with a Ho:YAG laser. We theorized from its physical properties that the Ho:YAG laser generated a greater area of inflammation without tissue destruction, thereby enhancing angiogenesis. That was our thought process in picking our laser.

In terms of preservation of ventricular function or ventricular volumes, if I understood your question correctly, some of the data that we found in addition (because of time constraints we were unable to present all of our data) indicated that there was greater preservation of ventricular diastolic diameter with TMR. This approached but did not reach statistical significance. 

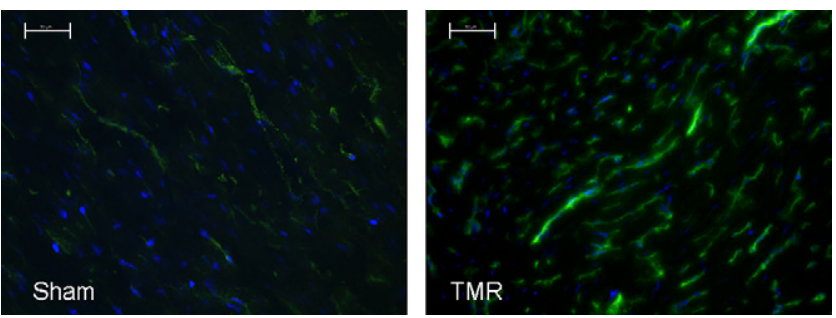

Figure E1. Therapy with transmyocardial laser revascularization (TMR) enhances myocardial vasculature. Representative immunofluorescent images of myocardium from ischemic left circumflex coronary myocardium of animals in sham and transmyocardial laser revascularization groups labeled for vasculature (green for CD31) and nuclei (blue for 4',6-diamidino-2-phenylindole) are demonstrated (original magnification $20 \times$; scale bar represents $50 \mu \mathrm{m})$. 